Article

\title{
New Spin-Crossover Compounds Containing the [Ni(mnt)] Anion (mnt = Maleonitriledithiolate)
}

\author{
Scott S. Turner ${ }^{1, *}$, Joanna Daniell ${ }^{1}$, Hiroki Akutsu ${ }^{2}{ }^{(D}$, Peter N. Horton ${ }^{3}$, Simon J. Coles ${ }^{3}$ \\ and Volker Schünemann 4
}

check for

updates

Citation: Turner, S.S.; Daniell, J.;

Akutsu, H.; Horton, P.N.; Coles, S.J.;

Schünemann, V. New Spin-Crossover

Compounds Containing the [Ni(mnt)] Anion (mnt = Maleonitriledithiolate) .

Magnetochemistry 2021, 7, 72.

https://doi.org/10.3390/

magnetochemistry7050072

Academic Editor: Marius Andruh

Received: 26 April 2021

Accepted: 14 May 2021

Published: 19 May 2021

Publisher's Note: MDPI stays neutral with regard to jurisdictional claims in published maps and institutional affiliations.

Copyright: (C) 2021 by the authors. Licensee MDPI, Basel, Switzerland. This article is an open access article distributed under the terms and conditions of the Creative Commons Attribution (CC BY) license (https:// creativecommons.org/licenses/by/ $4.0 /)$
1 Department of Chemistry, University of Surrey, Guildford GU2 7XH, UK; j.daniell@surrey.ac.uk

2 Department of Chemistry, Graduate School of Science, Osaka University, 1-1 Machikaneyama, Toyonaka, Osaka 560-0043, Japan; akutsu@chem.sci.osaka-u.ac.jp

3 EPSRC National Crystallographic Service, School of Chemistry, Faculty of Engineering and Physical Sciences, University of Southampton, Southampton SO17 1BJ, UK; P.N.Horton@soton.ac.uk (P.N.H.);

S.J.Coles@soton.ac.uk (S.J.C.)

4 Technische Universität Kaiserslautern, Erwin Schrödinger-Str 46, D-67663 Fachbereich Physik, Germany; schuene@physik.uni-kl.de

* Correspondence: s.s.turner@surrey.ac.uk

\begin{abstract}
Two novel salts containing the anion $\left[\mathrm{Ni}(\mathrm{mnt})_{2}\right]^{-}(\mathrm{mnt}=$ maleonitriledithiolate $)$ have been synthesized. The counter-ions, [ Fe(II)( $\mathbf{L}^{1}$ or $\left.\left.\mathbf{L}^{2}\right)_{2}\right]$, are cationic complexes where $\mathbf{L}^{\mathbf{1}}$ and $\mathbf{L}^{\mathbf{2}}$ are methylated derivatives of 2,6-bis(pyazolyl)pyridine or pyrazine, which are similar to ligands found in a series of spin-crossover (SCO) complexes. Both salts are characterized by variable temperature single crystal X-ray diffraction and bulk magnetization measurements. Compound $\mathbf{1},\left[\mathrm{Fe}(\mathrm{II})\left(\mathbf{L}^{\mathbf{1}}\right)_{2}\right]\left[\mathrm{Ni}(\mathrm{mnt})_{2}\right]_{2}$ displays an incomplete and gradual SCO up to $300 \mathrm{~K}$, followed by a more rapid increase in the high-spin fraction between 300 and $350 \mathrm{~K}$. Compound 2, $\left[\mathrm{Fe}(\mathrm{II})\left(\mathbf{L}^{2}\right)_{2}\right]\left[\mathrm{Ni}(\mathrm{mnt})_{2}\right]_{2} \cdot \mathrm{MeNO}_{2}$, shows a gradual, but more complete SCO response centered at $250 \mathrm{~K}$. For compound 2, the SCO is confirmed by variable temperature Mössbauer spectroscopy. In both cases, the anionic moieties are isolated from each other and so no electrical conductivity is observed.
\end{abstract}

Keywords: spin-crossover; molecular magnets; magnetic materials; molecular materials

\section{Introduction}

The phenomenon of spin-crossover (SCO) has been known since the 1930s, following the serendipitous work by Cambi et al. [1,2]. Contemporary interest in SCO is due to potential applications in data storage devices [3], sensors and displays. Their utility relies on electronic instability between high-spin (HS) and low-spin (LS) configurations in transition metal complexes with octahedral geometries and 4 to 7 valence d-electrons. Exploitable switching properties can be associated with SCO, for example color, magnetization $[4,5]$, dielectric constant [6,7], photo-physical properties [8-10], electrical conductivity [11] and structural parameters [12]. The most studied complexes contain Fe(II) and N-donor heterocyclic ligands, since spin state conversion in these compounds tend to give relatively large changes in properties [13,14]. In these cases, HS-LS switching also involves the maximal change in electron multiplicity, $S=0$ (LS) to $S=2$ (HS). A popular series of ligands in Fe(II) complexes, relevant to this work, has been 2,6-bis(pyrazol-1-yl)pyridine (dpp) and its derivatives, pioneered by Halcrow et al. [15-17].

In addition, SCO cationic complexes are attractive components of multifunctional hybrid salts when combined with anions that bring other properties, such as electrical conductivity or magnetic ordering [18]. This goes together with the development of molecular conductors where the conducting network is made from anionic moieties [19-21]. The goal is to obtain a molecular conductor that also exhibits SCO, such that the induced structural changes affect the materials ability to conduct electricity. Indeed, it is well-known that the electrical properties of molecular conductors are sensitive to small modifications of 
their crystal structure. There have been some successes in this area. For example, Fe(III) complexes of salycyl-type ligands [ $\mathrm{Fe}(\mathrm{III})\left(\mathrm{sal}_{2} \text {-trien)][Ni(dmit) }\right]_{\mathrm{n}}$ with $n=1$ [22-24] were the first materials to contain $[\mathrm{Ni}(\mathrm{dmit})]$ anions and $\mathrm{SCO}$ cations, although the compound did not conduct electricity, and when $n=3 \mathrm{SCO}$, it disappears with the appearance of semiconductivity [25]. The same group also made [Fe(III)(salten)-Mepepy][Ni(dmit) $\left.{ }_{2}\right]_{3}$, which had a gradual SCO associated with photoisomerization of the Mepepy ligand and moderated conductivity [26]. Takahashi et al. first observed a clear synergy between SCO and electrical conduction [27] in the related compound [Fe(III)(qsal) $\left.)_{2}\right]\left[\mathrm{Ni}(\mathrm{dmit})_{2}\right]_{3} \cdot \mathrm{CH}_{3} \mathrm{CN} \cdot \mathrm{H}_{2} \mathrm{O}$, qsalH $=\mathrm{N}$-(8-quinolyl)-salicyladimine. Generally, these early approaches focused on dmitbased anionic components with Fe(III) SCO complex cations, whereas, more recently, mnt-based anions (Scheme 1) have been used. Most notably, a compound closely related to those in this work, $\left[\mathrm{Fe}(\mathrm{II})(\mathrm{dpp})_{2}\right]\left[\mathrm{Ni}(\mathrm{III})(\mathrm{mnt})_{2}\right]_{2} \cdot \mathrm{MeNO}_{2}[28]$ was characterized by multistage spin-state conversions with mixed HS-LS states. A related $\mathrm{Fe}(\mathrm{II}) / \mathrm{Ni}(\mathrm{III})$ compound, $\left[\mathrm{Fe}(\mathrm{dppTTF})_{2}\right]\left[\mathrm{Ni}(\mathrm{mnt})_{2}\right]_{2}\left(\mathrm{BF}_{4}\right)_{2}$. PhCN, included a derivatized dpp with tetrathifulvalene (TTF) resulting in synergy between SCO and electrical conductivity [29]. In the current work, we focus on $\mathrm{Ni}$ (III) mnt-based anions with $\mathrm{Fe}(\mathrm{II})$ complex cations with methylated derivatives of dpp (Scheme $1, X=C$ ) and the related pyrazine $(X=N)$. This expansion is useful to investigate if the chemical flexibility, when derivatizing the dpp ligand, allows or disrupts SCO when metal complex anions are used.<smiles>Cc1cc(C)n(C2=C[X]C=CC(n3nc(C)cc3C)=N2)n1</smiles><smiles>N#CC1=C(C#N)S[N+]2(S1)SC(C#N)=C(C#N)S2</smiles>

Scheme 1. Ligands (left) used in this work, where $X=C$ (ligand $\mathbf{L}^{\mathbf{1}}$ ) and $X=\mathrm{N}\left(\mathbf{L}^{\mathbf{2}}\right)$. Mono-anionic complex, [Ni(III)(mnt) $\left.)_{2}\right]$, (right) used in this work.

\section{Results and Discussion}

\subsection{Description of Structures of Compounds 1 and 2}

Crystals amenable to single X-ray diffraction were obtained of compound $\mathbf{1},\left[\mathrm{Fe}(\mathrm{III})\left(\mathbf{L}^{\mathbf{1}}\right)_{2}\right]$ $\left[\mathrm{Ni}(\mathrm{mnt})_{2}\right]_{2}$ and compound $2, \quad\left[\mathrm{Fe}(\mathrm{II})\left(\mathrm{L}^{2}\right)_{2}\right]\left[\mathrm{Ni}(\mathrm{mnt})_{2}\right]_{2} \cdot \mathrm{MeNO}_{2}$, as detailed in Sections 3.1 and 3.2. For both compounds, the structures were solved at 100 and ca. $290 \mathrm{~K}$. Both compounds crystalize in the P-1 (No. 2) space group. Table 1 contains the relevant crystallographic data and collection parameters. Figures 1 and 2 show the molecular structures of both compounds at $100 \mathrm{~K}$, with thermal ellipsoids and the atom numbering scheme referred to in the text. The asymmetric unit of compound $\mathbf{1}$ contains one crystallographically independent $\mathrm{Fe}(\mathrm{II})$ cation, two $\left[\mathrm{Ni}(\mathrm{mnt})_{2}\right]^{-}$anions and no included solvent. By contrast, compound 2 contains the same 1:2 Fe(II): Ni(III) metal complex ratio with the additional inclusion of one $\mathrm{CH}_{3} \mathrm{NO}_{2}$ molecule.

For compound 1, the coordination geometry about the Fe(II) cation has a distorted octahedral $\mathrm{FeN}_{6}$ environment. From the point of view of SCO, it is important to look at the $\mathrm{Fe}-\mathrm{N}$ bond lengths, which reflect the spin-state [12]. In compound 1, at $100 \mathrm{~K}$, these bond lengths range from 1.889 to $1.987 \AA$ (average $1.957 \AA$ ). At $293 \mathrm{~K}$, there is little change, with the bond lengths varying between 1.891 and $1.987 \AA$ (average $1.954 \AA$ ). At both temperatures, this is indicative of a LS-state Fe(II) center. In addition, a change in the distortion from ideal local octahedral geometry can indicate a spin-state change. The OctoDist program [30] was used to determine the distortion parameters. The first parameter, $\Sigma$, is the sum of the deviations from $90^{\circ}$ of the twelve cis $\mathrm{N}-\mathrm{Fe}-\mathrm{N}$ angles. A second parameter, $\Theta$, is the sum of the deviations from $60^{\circ}$ of the twenty-four N-Fe-N angles, six per pseudo three-fold axis, measured on a projection of opposite triangular 
faces of the $\mathrm{FeN}_{6}$ octahedron, orientated by superimposing the face centroids. Typically, $\Sigma$ and $\Theta$ are lower for LS and higher for more distorted HS complexes [12]. For compound $1, \Sigma$ is $87.09^{\circ}$ at $100 \mathrm{~K}$ and $87.16^{\circ}$ at $293 \mathrm{~K}$, essentially unchanged. Similarly, $\Theta$ is $287.00^{\circ}$ at $100 \mathrm{~K}$ and $285.14^{\circ}$ at $293 \mathrm{~K}$ is also unchanged. These structural parameters indicate LS complexes at both temperatures and do not reflect the SCO found from magnetization data (Section 2.2), most likely due to the substantially incomplete nature of the transition.

Table 1. Crystallographic data and collection parameters for compounds $\mathbf{1}$ and $\mathbf{2 .}$

\begin{tabular}{|c|c|c|c|c|}
\hline Parameter & \multicolumn{2}{|c|}{ Compound 1} & \multicolumn{2}{|c|}{ Compound 2} \\
\hline Empirical formula & \multirow{2}{*}{\multicolumn{2}{|c|}{$\begin{array}{c}\mathrm{C}_{46} \mathrm{H}_{34} \mathrm{~N}_{18} \mathrm{~S}_{8} \mathrm{FeNi}_{2} \\
1268.66\end{array}$}} & \multirow{2}{*}{\multicolumn{2}{|c|}{$\begin{array}{c}\mathrm{C}_{45} \mathrm{H}_{35} \mathrm{~N}_{21} \mathrm{~S}_{8} \mathrm{O}_{2} \mathrm{FeNi}_{2} \\
1331.64\end{array}$}} \\
\hline Molecular Mass & & & & \\
\hline $\mathrm{T} / \mathrm{K}$ & $100(2)$ & 293(2) & $100(2)$ & $290(2)$ \\
\hline CCDC number & 2080108 & 2080109 & 2080110 & 2080111 \\
\hline Crystal color \& shape & \multicolumn{2}{|c|}{ Brown Plate } & \multicolumn{2}{|c|}{ Black Prism } \\
\hline Crystal system & \multicolumn{2}{|c|}{ Triclinic } & \multicolumn{2}{|c|}{ Triclinic } \\
\hline Space Group & \multicolumn{2}{|c|}{$P-1(2)$} & \multicolumn{2}{|c|}{$P-1(2)$} \\
\hline $\mathrm{a} / \AA$ & $11.1318(3)$ & $11.2229(5)$ & $13.3643(6)$ & $13.4983(8)$ \\
\hline $\mathrm{b} / \AA$ & $12.1322(4)$ & $12.3046(6)$ & $14.7900(6)$ & $15.1017(10)$ \\
\hline $\mathrm{c} / \AA$ & $19.4594(6)$ & $19.6208(7)$ & $14.9875(8)$ & 15.1633(9) \\
\hline$\alpha /^{\circ}$ & $94.543(2)$ & $93.625(3)$ & $79.731(6)$ & $79.756(6)$ \\
\hline$\beta /{ }^{\circ}$ & $90.216(2)$ & $89.349(3)$ & $81.844(6)$ & $81.882(6)$ \\
\hline$\gamma /{ }^{\circ}$ & $92.986(2)$ & 90.932(4) & $69.962(5)$ & $68.796(3)$ \\
\hline Volume $/ \AA^{3}$ & $2616.16(14)$ & $2703.6(2)$ & 2728.01(15) & $2825.8(3)$ \\
\hline Wavelength/ & \multicolumn{2}{|c|}{0.71075} & \multicolumn{2}{|c|}{0.71075} \\
\hline Radiation Type & \multicolumn{2}{|c|}{ Mo K $\alpha$} & \multicolumn{2}{|c|}{ Mo K $\alpha$} \\
\hline $\mathrm{Z}$ & 2 & 2 & 2 & 2 \\
\hline$\mu / \mathrm{mm}^{-1}$ & 1.360 & 1.316 & 1.312 & 1.267 \\
\hline Measured reflections & 33346 & 35619 & 26321 & 27746 \\
\hline Independent reflections & 11866 & 12326 & 12418 & 12853 \\
\hline Reflections $\mathrm{I} \geq 2 \sigma(\mathrm{I})$ & 7764 & 6982 & 7709 & 6893 \\
\hline$w \mathrm{R}_{1}$ (all data) & 0.0956 & 0.1109 & 0.0828 & 0.1435 \\
\hline $\mathrm{R}_{1}, \mathrm{I} \geq 2 \sigma(\mathrm{I})$ & 0.0496 & 0.0528 & 0.0456 & 0.0772 \\
\hline
\end{tabular}

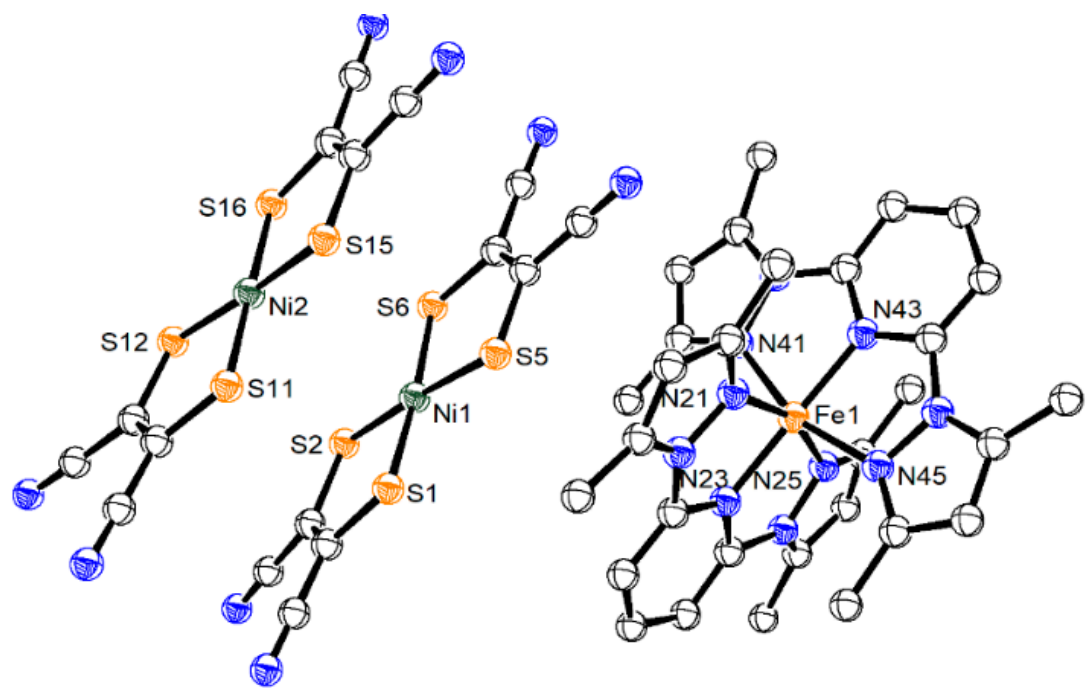

Figure 1. The molecular structure of compound 1 at $100 \mathrm{~K}$, in the ORTEP [29] style with 50\% thermal ellipsoids and atom numbering scheme. $\mathrm{H}$ atoms have been omitted for clarity. 


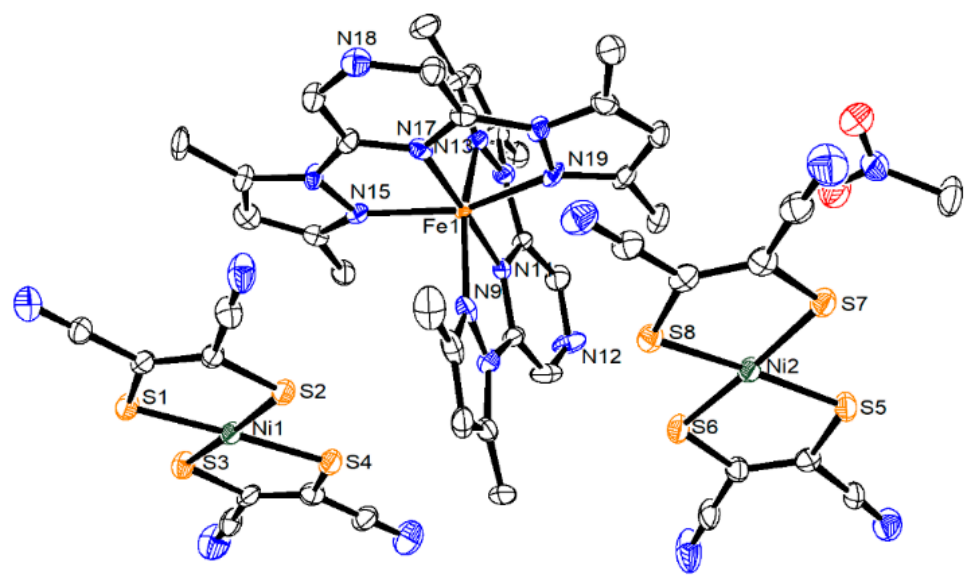

Figure 2. The molecular structure of compound 2 at $100 \mathrm{~K}$, in the ORTEP [29] style with 50\% thermal ellipsoids and atom numbering scheme. $\mathrm{H}$ atoms have been omitted for clarity.

At both temperatures, the overall structure of compound 1 consists of alternating layers of cations and anions when viewed down the crystallographic $a b$ plane, as seen in Figure 3. The anionic Ni layer consists of discrete dimers that occupy cavities created by the cations, with close S . . S contacts between dimers. At $100 \mathrm{~K}$, these are $3.393 \AA$ between S1 and S11, and $3.526 \AA$ between S6 and S16 with significantly longer distances to the next nearest dimer. The anionic charge, and by extension the Ni oxidation state, can be correlated with the geometry, specifically the Ni-S bond lengths since these are affected by the electron population of the molecular orbitals. For compound 1, the two crystallographically independent anions have similar bond lengths that are compatible with mono-anions and $\mathrm{Ni}(\mathrm{III})$. The bond lengths range from 2.135 to $2.143 \AA$ at $293 \mathrm{~K}$ and 2.139 to $2.151 \AA$ at $100 \mathrm{~K}$, whereas large bond lengths of ca. $2.17 \AA$ are found for $\left[\mathrm{Ni}(\mathrm{II})(\mathrm{mnt})_{2}\right]^{2-}[31]$.

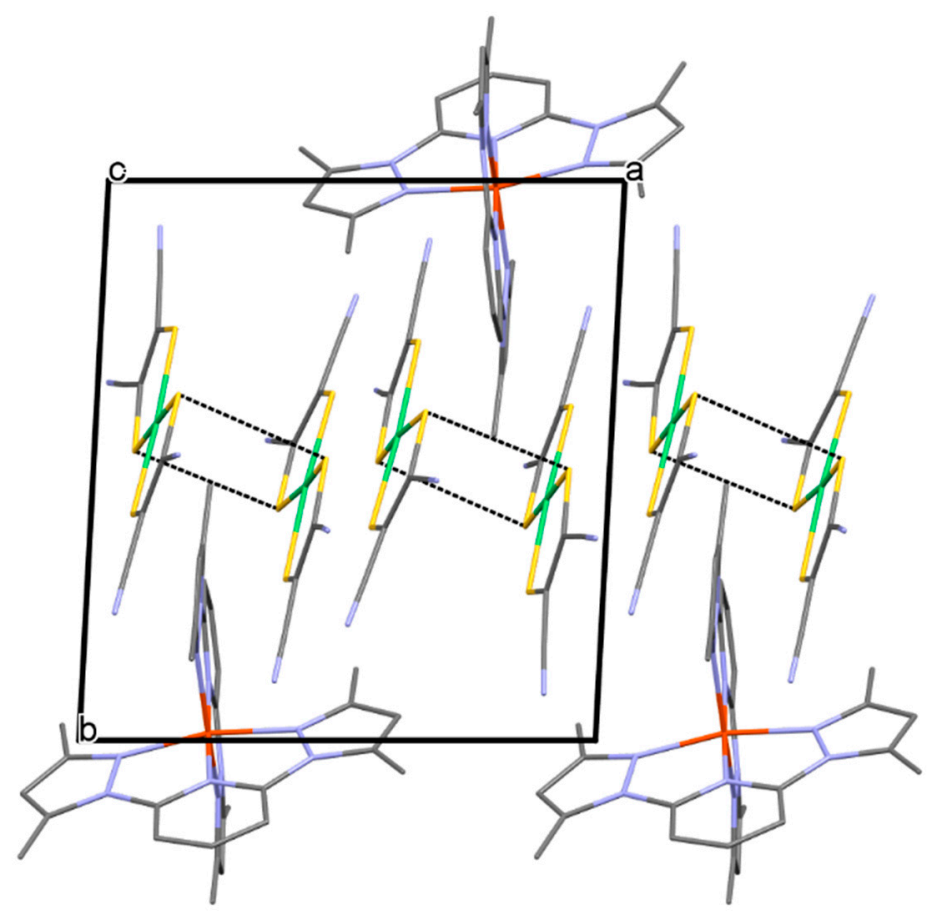

Figure 3. The crystal packing of compound 1 at $100 \mathrm{~K}$. Short contacts between $\mathrm{S}$ atoms are indicated by black dotted lines. $\mathrm{H}$ atoms have been omitted for clarity. 
For compound 2, the complex geometry about Fe(II) is also a distorted octahedron, but in this case, there is a variation in Fe-N bond lengths as a function of temperature. At $100 \mathrm{~K}$, the bond lengths vary from 1.967 to $2.070 \AA$ with an average of $2.030 \AA$. However, there is an increase at $290 \mathrm{~K}$ to an average of $2.102 \AA$ with a minimum bond length of 2.047 and a maximum of $2.136 \AA$. This change reflects the spin-state change that is seen in the bulk magnetism and Mössbauer data vide infra. In addition, there is a clear distortion of the octahedral geometry between the two temperatures. The parameter $\Sigma$ is $109.14^{\circ}$ at $100 \mathrm{~K}$, meaning that the LS state of compound 2 has an intrinsically more distorted geometry than the LS state of compound 1. However, at $290 \mathrm{~K}$, this significantly increases to $132.94^{\circ}$, which is indicative of a spin-state change. Additionally, an increase was seen in the distortion parameter $\Theta$ of $354.66^{\circ}$ at $100 \mathrm{~K}$, but is $428.34^{\circ}$ at $290 \mathrm{~K}$. Furthermore, Halcrow suggested that whole molecule deviation from ideal $\mathrm{D}_{2 \mathrm{~d}}$ symmetry in $\mathrm{HS}\left[\mathrm{Fe}(\mathrm{dpp})_{2}\right]^{2+}$-like cations indicates a propensity to undergo SCO [12]. The contention is that HS structures that deviate too much from the typical distortion seen at LS are unable to undergo SCO, although this analysis is not definitive. The distortion from $\mathrm{D}_{2 \mathrm{~d}}$ is parametized by the trans-N(pyridyl)-Fe-N(pyridyl) angle $(\theta)$ and the dihedral angle between ligand mean planes $(\phi)$. For compound 2, parameter $\theta$ is $178.43(100 \mathrm{~K})$ and $178.11^{\circ}(293 \mathrm{~K})$, whereas $\phi$ is $84.84^{\circ}(100 \mathrm{~K})$ and $85.20^{\circ}(24=93 \mathrm{~K})$. The HS and LS values do not deviate far from each other, and therefore compound 2 is not an outlier in undergoing SCO [11].

In comparison to compound 1, the anions and cations of compound $\mathbf{2}$ are not clearly separated into layers, since the two ions tend to interdigitate with each other. Correspondingly, there are no short $S$.. S contacts between anions, the shortest $S$... S distance being $3.926 \AA$, so that each Ni anion is isolated from the nearest neighbor (Figure 4). The Ni-S bond lengths are similar for both crystallographically independent anions, indicating that they have the same charge and metal oxidation state. The values range from 2.138 to $2.155 \AA$ at $290 \mathrm{~K}$ and 2.141 to $2.161 \AA$ at $100 \mathrm{~K}$, typical for a Ni(III) monoanion [31].

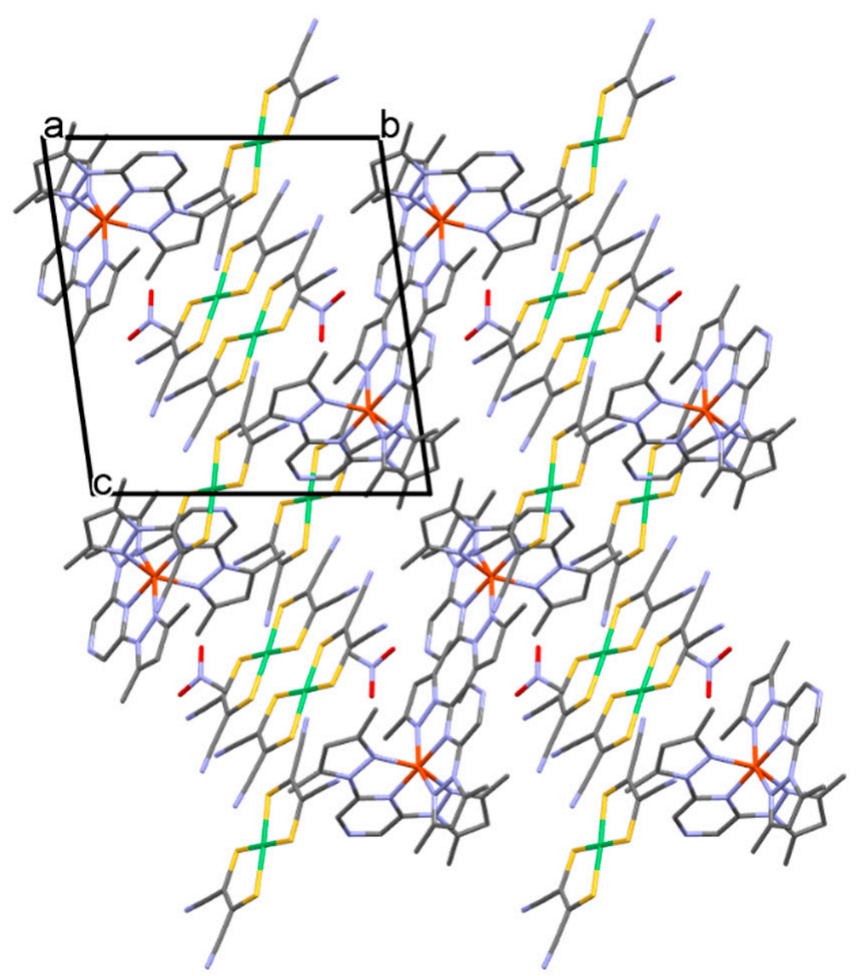

Figure 4. The crystal packing of compound 2 at $100 \mathrm{~K}$. H atoms have been omitted for clarity. 
In both compound $\mathbf{1}$ and $\mathbf{2}$, the arrangement and isolation of the anions means that it is unlikely that these compounds would display electrical conduction, as observed in some mnt-containing structures with more evenly distributed layering. This is evident from preliminary 2-probe resistance measurements, which give values above the limit of our equipment $(1 \mathrm{M}$ ohm $)$ in three perpendicular directions through the crystals at $300 \mathrm{~K}$.

\subsection{Magnetic Properties}

Figure 5 shows the magnetic data for compound $\mathbf{1},\left[\mathrm{Fe}\left(\mathrm{L}^{1}\right)_{2}\right]\left[\mathrm{Ni}(\mathrm{mnt})_{2}\right]_{2}$ and $2,\left[\mathrm{Fe}\left(\mathrm{L}^{2}\right)_{2}\right]\left[\mathrm{Ni}(\mathrm{mnt})_{2}\right]_{2} \cdot \mathrm{MeNO}_{2}$, expressed as the temperature $(\mathrm{T})$ dependence of the product $\chi_{\mathrm{m}} \mathrm{T}$, where $\chi_{\mathrm{m}}$ is the molar magnetic susceptibility. An initial analysis of the data can assume no magnetic exchange at higher temperatures. The magnetic data would then be a summation of contributions from HS Fe(II) $(S=2), \operatorname{LS} \mathrm{Fe}(\mathrm{II})(S=0)$ and two $\left[\mathrm{Ni}(\mathrm{III})(\mathrm{mnt})_{2}\right]$ anions $(S=1 / 2$ each). At lower temperatures there may also be a magnetic exchange that reduces or increases the contribution.
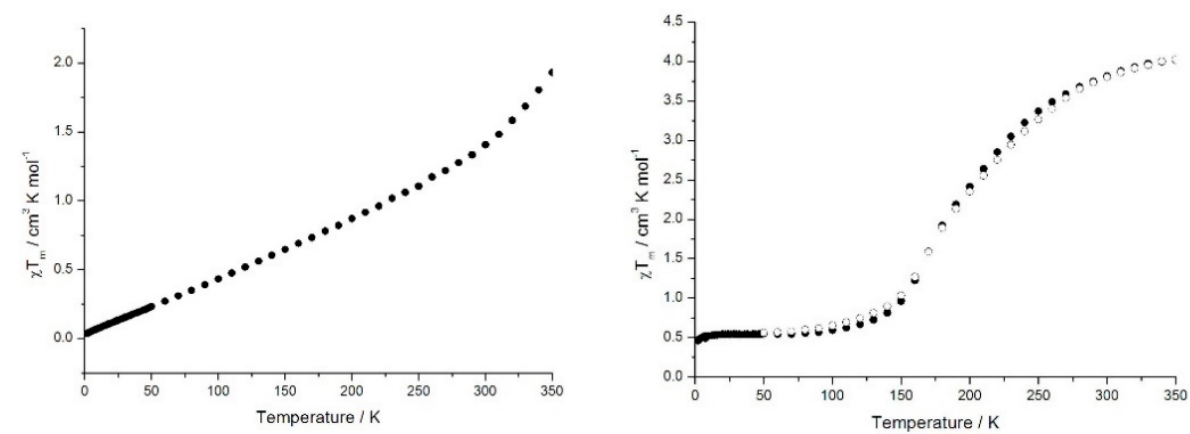

Figure 5. Temperature dependence of the product $\chi_{m} T$ for compound $\mathbf{1}$ (left) and compound $\mathbf{2}$ (right). Full circles are measurements of warmings from 2 to $350 \mathrm{~K}$, while open circles are measurements and there is cooling across the same temperature range.

For compound 1, at $2 \mathrm{~K}$ the value of $\chi_{m} T$ is $0.04 \mathrm{~cm}^{3} \mathrm{~K} \mathrm{~mol}^{-1}$, which implies that $\mathrm{Fe}(\mathrm{II})$ is in the LS state and there is also little contribution from the Ni anionic moieties. The reason for the small contribution from the anions is most likely linked to their dimerization and subsequent antiferromagnetic coupling. On warming, there is a steady, almost linear increase in $\chi_{m} T$ up to about $300 \mathrm{~K}\left(1.41 \mathrm{~cm}^{3} \mathrm{~K} \mathrm{~mol}^{-1}\right)$, followed by a more rapid rise to $350 \mathrm{~K}$ where the maximum $\chi_{m} T$ is $1.93 \mathrm{~cm}^{3} \mathrm{~K} \mathrm{~mol}^{-1}$. These higher values cannot be achieved by a simple loss of antiferromagnetic coupling between anions, which would lead to a maximum $\chi_{m} T$ value of $0.75 \mathrm{~cm}^{3} \mathrm{~K} \mathrm{~mol}^{-1}$. Therefore, there must be an increased contribution from HS $\mathrm{Fe}(\mathrm{II})$ as the temperature rises. Nevertheless, this is an incomplete SCO and is not reflected in the variable temperature structural data of compound 1. Such behavior has been previously seen in $\left[\mathrm{FeL}_{2}\right]\left(\mathrm{ClO}_{4}\right)_{2}$, where $\mathrm{L}=2$,6-bis(3-methylpyrazol-1-yl)pyrazine [32].

Compound 2 distinctly shows different behavior. At $2 \mathrm{~K}$, the value of $\chi_{m} T$ is $0.46 \mathrm{~cm}^{3} \mathrm{~K} \mathrm{~mol}^{-1}$, which rises slightly and reaches $0.5 \mathrm{~cm}^{3} \mathrm{~K} \mathrm{~mol}^{-1}$ after $100 \mathrm{~K}$, after which there is a more rapid rise to a maximum value of $4.02 \mathrm{~cm}^{3} \mathrm{~K} \mathrm{~mol}^{-1}$ at $350 \mathrm{~K}$. We can estimate the g-value for the Fe complex using the Mossbauer data and bulk magnetic data at $300 \mathrm{~K}$. The Mossbauer data (Section 2.3) indicates that $83 \%$ of the Fe(II) complex is in the HS state at $300 \mathrm{~K}$, whereas the bulk magnetic data gives a total $\chi_{m} T$ of $3.82 \mathrm{~cm}^{3} \mathrm{~K}$ $\mathrm{mol}^{-1}$ at the same temperature. Assuming this high temperature $\chi_{m} T$ value also includes contributions from two independent $\left[\mathrm{Ni}(\mathrm{mnt})_{2}\right]$ anions (total $0.75 \mathrm{~cm}^{3} \mathrm{~K} \mathrm{~mol}^{-1}$ ), then $3.07 \mathrm{~cm}^{3} \mathrm{~K} \mathrm{~mol}^{-1}$ is the contribution from $83 \%$ of a S $=2 \mathrm{HS} \mathrm{Fe}(\mathrm{II})$ and $17 \% \mathrm{~S}=0 \mathrm{LS} \mathrm{Fe}(\mathrm{II})$. This gives an estimate of $\mathrm{g}$ of 2.2 using $\chi_{m} T=0.83 \times 0.12505 \mathrm{~g}^{2} \mathrm{~S}(\mathrm{~S}+1)$. Using this $\mathrm{g}$ value and the same calculation, with the \% fraction HS as the unknown, we can estimate the HS fraction to be $90 \%$ at $350 \mathrm{~K}$ and $46 \%$ at $200 \mathrm{~K}$. Below about $100 \mathrm{~K}$, the Fe(II) centers are mostly in the LS state and this does not contribute to the magnetism. The small value of $\chi_{m} T$ further implies an antiferromagnetic coupling between $\left[\mathrm{Ni}(\mathrm{mnt})_{2}\right]$ anions, albeit 
weaker than that shown by compound 1. Indeed, the data below $80 \mathrm{~K}$ follows a Curie-Weiss law, with a negative Weiss constant of $-0.6 \mathrm{~K}$. However, bulk magnetization data is not an ideal method of decoupling the contributions from the $\mathrm{Ni}$ and Fe ions, but the above calculation of the HS fraction at $200 \mathrm{~K}$ agrees well with Mössbauer data vida infra. Finally, on measuring while cooling and warming the curves for compound 2 are essentially identical with no hysteresis, it reflects the lack of inter-cation short contacts in the structure. We can make some speculations as to the origin of the difference in abruptness of the SCO between the two salts. The compounds have cations with a very small molecular change; a $\mathrm{CH}$ in compound $\mathbf{1}$ is replaced by a $\mathrm{N}$ atom in compound 2 . This is unlikely to be directly responsible for such a difference in SCO, where more abrupt transitions are correlated to increased intermolecular interactions. However, the inclusion of the solvent in compound 2, along with the overall change in packing, is likely to be more relevant. Compound 1, with a much more gradual SCO, has a clear 2D layered structure, but the more abrupt SCO for compound $\mathbf{2}$ is associated with a more 3D structure, although both do not have any substantive inter-cation interactions. It is suggested that the more abrupt SCO for compound $\mathbf{2}$ is a result of the 3D organization, whereas the very gradual SCO for compound $\mathbf{1}$ is a response to more isolation of cations into layers.

\subsection{Mössbauer Spectroscopy}

The variable temperature ${ }^{57}$ Fe Mössbauer data for compound 2 is presented in Figure 6. The associated hyperfine parameters were found by a least-squares fit, assuming Lorentzian shaped peaks, and are given in Table 2. Measurements were taken at several temperatures between 300 and $100 \mathrm{~K}$ but Figure 6 shows the fitted data at 300 K, $200 \mathrm{~K}$ and $100 \mathrm{~K}$. All spectra were found to have signals that are attributable to both HS and LS Fe(II) complexes.

The experimental data is given as black dots. The signal for the HS Fe(II) having the largest quadrupole splitting (Table 2) is modelled by the green curve. The signal for the LS Fe(II) with the smallest quadrupole splitting is modelled by the blue curve. In each case, the hyperfine parameters compare well with the expected values. The red curve is the sum of the contributions from both the HS and LS Fe(II) curves and maps well onto the experimental data. The portion of the HS and LS complexes vary, as expected from the SQUID magnetic data. The measurements at 300 and $200 \mathrm{~K}$ clearly show two quadrupole doublets, indicating the presence of significant quantities of both HS and LS Fe(II) centers. An analysis of the integrals of the modelled curves indicates, at $300 \mathrm{~K}$, that there is $83 \%$ of the HS fraction and $17 \%$ of the LS fraction. At $200 \mathrm{~K}$, there is approximately $50 \%$ of each, and only $1.8 \%$ of the HS complex remains at $100 \mathrm{~K}$. These percentage fractions are very close to those proposed from bulk magnetic data. Figure 7 shows all the Mössbauer data replotted to show the temperature variation of the HS fraction. This data confirms the conversion from almost complete LS Fe(II) at $100 \mathrm{~K}$ to a HS/LS mixture at $300 \mathrm{~K}$, albeit with an excess of HS Fe(II). The transition temperature seen in Figure 7 also compares well with the bulk magnetic data in Figure 5. 

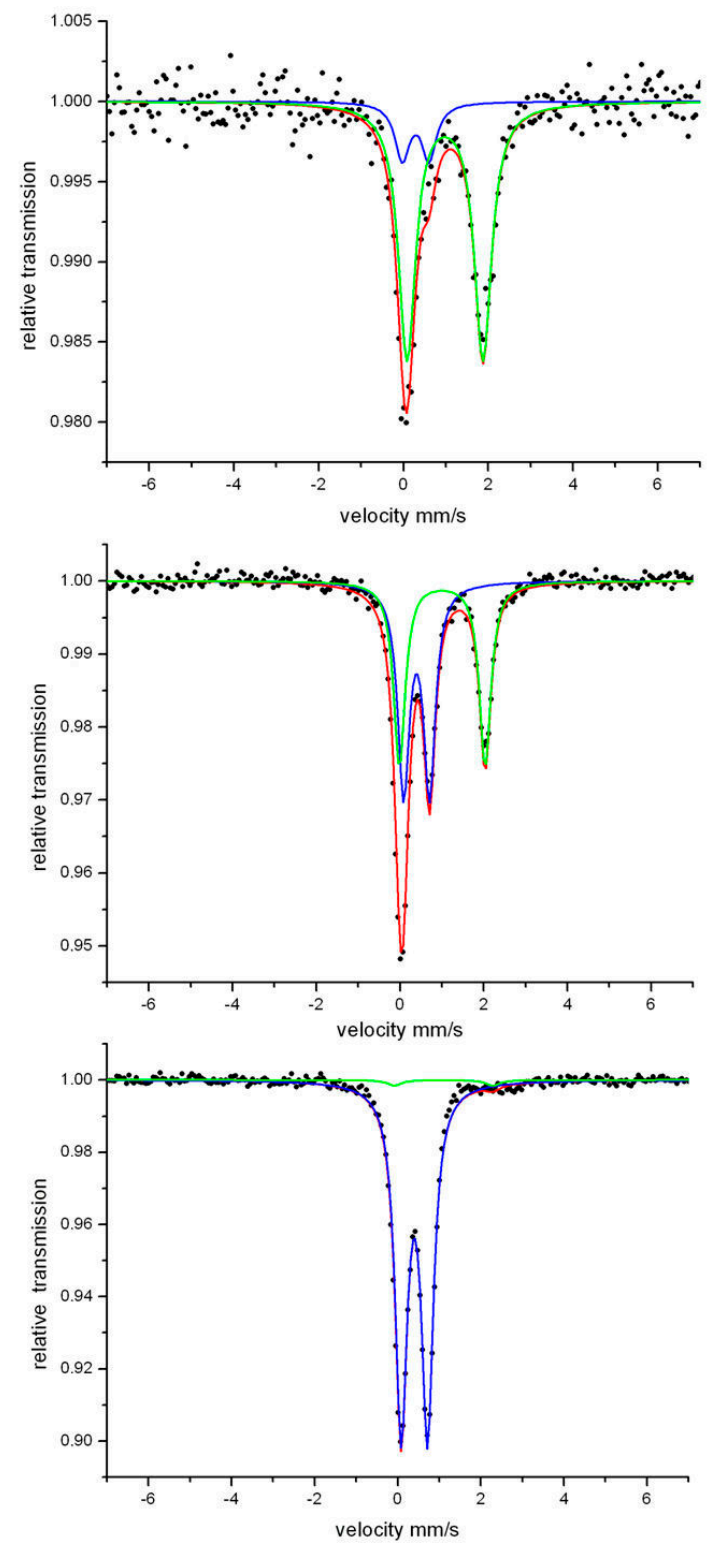

Figure 6. Mössbauer spectra of compound 2, at $300 \mathrm{~K}$ (top), $200 \mathrm{~K}$ (middle) and $100 \mathrm{~K}$ (bottom). Experimental data are in black dots and the lines are data fitted, giving the parameters listed in Table 2. Fitting curves are low-spin (blue), high-spin (green) and total (red).

Table 2. Fitting parameters for variable temperature Mössbauer spectra ${ }^{1}$ for compound 2.

\begin{tabular}{ccccc}
\hline Temperature/K & Spin State & $\boldsymbol{\delta}$ & $\boldsymbol{\Delta} \boldsymbol{E}_{\boldsymbol{Q}}$ & $\boldsymbol{\Gamma}$ \\
\hline \multirow{2}{*}{300} & HS & 0.98 & 1.78 & 0.49 \\
& LS & 0.29 & 0.64 & 0.42 \\
\multirow{2}{*}{200} & HS & 1.01 & 2.05 & 0.34 \\
& LS & 0.39 & 0.63 & 0.34 \\
& HS & 1.10 & 2.38 & 0.40 \\
& LS & 0.40 & 0.64 & 0.35 \\
\hline
\end{tabular}

${ }^{1} \delta$ is the isomer shift $\left( \pm 0.02 \mathrm{~mm} \mathrm{~s}^{-1}\right), \Delta E_{Q}$ is the quadrupole splitting $\left( \pm 0.02 \mathrm{~mm} \mathrm{~s}^{-1}\right)$ and $\Gamma$ is the full width and has the maximum of the peaks $\left( \pm 0.03 \mathrm{~mm} \mathrm{~s}^{-1}\right)$. HS = high spin. LS = low spin. 


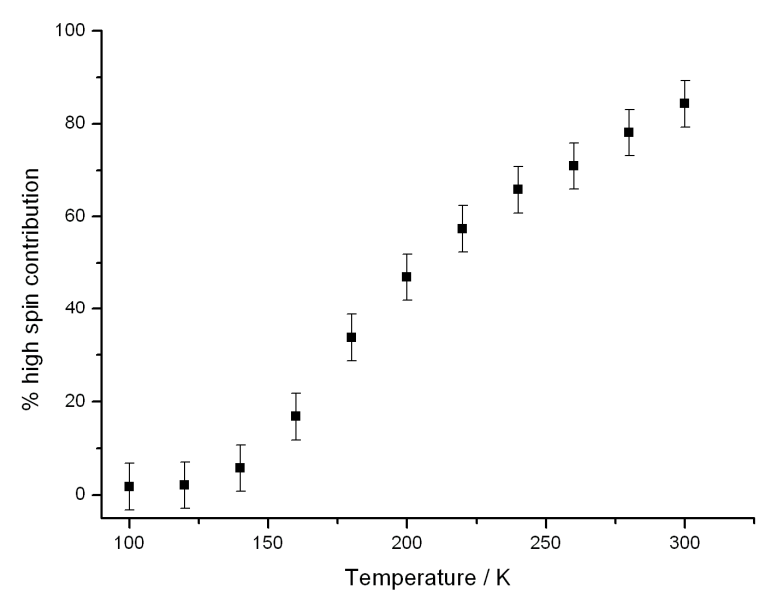

Figure 7. Graph derived from integral analysis of the Mössbauer data, showing temperature variation of the high-spin Fe(II) fraction in compound 2.

\section{Materials and Methods}

All reactions were completed in air, unless otherwise stated, using commercial grade chemicals. $\left(\mathrm{C}_{4} \mathrm{H}_{9}\right)_{4} \mathrm{~N}\left[\mathrm{Ni}(\mathrm{mnt})_{2}\right]$ was purchased from Tokyo Chemicals Industry (TCI) and was used as received. All other chemicals were purchased from Sigma-Aldrich and used as received. Magnetization measurements were completed using a MPMS-5 SQUID magnetometer (Quantum Design, CA, USA) with powdered samples held in gelatin capsules in an external field of $0.1 \mathrm{~T}$. Each sample was cooled to $2 \mathrm{~K}$ and measured while being warmed to $300 \mathrm{~K}$. Since compound 2 had a more abrupt SCO, this sample was also measured while cooling in order to determine hysteresis. Diamagnetic corrections were made for the sample holder and for the compound, the latter estimated using Pascals constants [33]. Resistance measurements were made using a two-probe method, at ambient temperature, with gold wire (diam $1 \mu \mathrm{m}$ ) attached to the opposite sides of a crystal with carbon paste. This was measured using a Keithley Instruments 6517A multimeter (Tektronics, UK). For compound 1, single crystal X-ray diffraction was performed using a Rigaku AFC12 goniometer and enhanced sensitivity Saturn724+ detector with Superbright Mo rotating anode generator. Structure refinement was completed using SHELXL [34]. For compound 2, single crystal X-ray diffraction was performed using a Rapid II imaging plate system with MicroMax-007 $\mathrm{HF}$ / VariMax rotating anode X-ray generator and confocal monochromated Mo-Ka radiation. Structure refinement was completed with SHELXL [34] or CRYSTALS [35] software. All non-hydrogen atoms were refined anisotropically. Hydrogen atom positions were calculated geometrically and refined using the riding model. Mössbauer spectra were recorded using a conventional spectrometer in the constant-acceleration mode. Isomer shifts are given relative to $\alpha$-Fe. Temperature dependent Mössbauer spectra were recorded with a closed-cycle cryostat (CRYO Industries of America Inc., USA) and were analyzed by the least-square fits using Lorentzian line shapes. CHN elemental analysis was performed using an CE-440 Elemental Analyzer (Exeter Analytical Inc., Coventry, UK).

\subsection{Synthesis of Ligands and Fe(II) Complexes}

The ligand $\mathbf{L}^{\mathbf{1}}$ was prepared by the literature procedure [36], although using the workup methods later described by Halcrow et al [15]. The ligand $\mathbf{L}^{2}$ was prepared following the procedure by Halcrow et al. [32]. The reaction of $\mathrm{Fe}\left(\mathrm{BF}_{4}\right)_{2} \cdot 6 \mathrm{H}_{2} \mathrm{O}$ was done by stirring for two hours in acetone with two equivalents of $\mathbf{L}^{\mathbf{1}}$ or $\mathbf{L}^{2}$, followed by precipitation by adding diethyl ether yielded brown solids. The color indicates that both $\left[\mathrm{Fe}\left(\mathrm{L}^{\mathbf{1}}\right)_{2}\right]\left(\mathrm{BF}_{4}\right)_{2}$ and $\left[\mathrm{Fe}\left(\mathbf{L}^{2}\right)_{2}\right]\left(\mathrm{BF}_{4}\right)_{2}$ are in the LS state at ambient temperature.

\subsection{Synthesis of Compounds $\mathbf{1}$ and $\mathbf{2}$}

Compounds 1 and 2 were produced using a moderated procedure from Oshio et al. [11]. For compound 1, $\left[\mathrm{Fe}\left(\mathbf{L}^{\mathbf{1}}\right)_{2}\right]\left(\mathrm{BF}_{4}\right)_{2}(38.2 \mathrm{mg}, 0.05 \mathrm{mmol})$ in $\mathrm{MeNO}_{2}(5 \mathrm{~mL})$ was added drop- 
wise to a solution of $\left(\mathrm{C}_{4} \mathrm{H}_{9}\right)_{4} \mathrm{~N}\left[\mathrm{Ni}(\mathrm{mnt})_{2}\right](69.7 \mathrm{mg}, 0.12 \mathrm{mmol})$ in $\mathrm{MeNO}_{2}(10 \mathrm{~mL})$. The resulting dark green/brown solution was kept at $-20{ }^{\circ} \mathrm{C}$ overnight to yield a dark brown microcrystalline powder, which was collected and washed with cold $\mathrm{MeNO}_{2}$. Recrystallisation was achieved by redissolving the solid in hot $\mathrm{MeNO}_{2}$, followed by cooling at $-20{ }^{\circ} \mathrm{C}$ to give thin brown plate-like crystals. Yield $64 \%$. Found C, 43.18; H, 2.02; N, 19.42. Calcd for $\left[\mathrm{Fe}\left(\mathbf{L}^{\mathbf{1}}\right)_{2}\right]\left[\mathrm{Ni}(\mathrm{mnt})_{2}\right]_{2}, \mathrm{C}_{46} \mathrm{H}_{34} \mathrm{~N}_{18} \mathrm{~S}_{8} \mathrm{FeNi}_{2}: \mathrm{C}, 43.55 ; \mathrm{H}, 2.00 ; \mathrm{N}, 19.87$.

Compound 2 was prepared by a similar procedure except using $\left[\mathrm{Fe}\left(\mathbf{L}^{2}\right)_{2}\right]\left(\mathrm{BF}_{4}\right)_{2}$ in place of $\left[\mathrm{Fe}\left(\mathbf{L}^{\mathbf{1}}\right)_{2}\right]\left(\mathrm{BF}_{4}\right)_{2}$. In this case, small black prism-shaped crystals precipitated after standing for 2 hours, without the need for cooling. Yield 58\%. Found C, 40.85; H, 2.60; N, 22.19. Calcd for $\left[\mathrm{Fe}\left(\mathrm{L}^{2}\right)_{2}\right]\left[\mathrm{Ni}(\mathrm{mnt})_{2}\right]_{2} \cdot \mathrm{MeNO}_{2}, \mathrm{C}_{45} \mathrm{H}_{35} \mathrm{~N}_{21} \mathrm{~S}_{8} \mathrm{O}_{2} \mathrm{FeNi}_{2}: \mathrm{C}, 40.59 ; \mathrm{H}, 2.65 ; \mathrm{N}, 22.09$.

\section{Conclusions}

Two novel salts have been synthesized: compound $\mathbf{1}$ with formula $\left[\mathrm{Fe}\left(\mathbf{L}^{\mathbf{1}}\right)_{2}\right]\left[\mathrm{Ni}(\mathrm{mnt})_{2}\right]_{2}$ and compound $\mathbf{2}$ with formula $\left[\mathrm{Fe}\left(\mathbf{L}^{2}\right)_{2}\right]\left[\mathrm{Ni}(\mathrm{mnt})_{2}\right]_{2} \cdot \mathrm{MeNO}_{2}$. $\mathbf{L}^{\mathbf{1}}$ and $\mathbf{L}^{2}$, which are methylated derivatives of a series of ligands that are present in several $\mathrm{Fe}(\mathrm{II})$ complexes that exhibit SCO, albeit such salts typically have simple counterions such as $\mathrm{BF}_{4}$ and $\mathrm{ClO}_{4}$. Bulk magnetization studies indicate that both compounds $\mathbf{1}$ and $\mathbf{2}$ show SCO. However, for compound 1, the SCO is incomplete up to $350 \mathrm{~K}$ and only represents a small conversion from the LS to HS state. Consequently, there is little evidence from variable temperature single crystal structural data that the typical structural transitions that accompany SCO are fully developed. By contrast, bulk magnetization measurements on compound $\mathbf{2}$ show that the compound is in the LS state below $100 \mathrm{~K}$ and almost completely HS at $350 \mathrm{~K}$. The associated Fe-ligand bond length changes and geometry distortions are clearly observed even at $290 \mathrm{~K}$, when most of the Fe complexes are in the HS state. Furthermore, the SCO in compound $\mathbf{2}$ is confirmed using Mossbauer spectroscopy. The introduction of the $\left[\mathrm{Ni}(\mathrm{mnt})_{2}\right]$ anion illustrates the chemical flexibility and robust nature of SCO in these types of $\mathrm{Fe}(\mathrm{II})$ complexes. It also points to the possibility of incorporating secondary functionality into SCO materials.

Author Contributions: Conceptualization, methodology, analysis and article preparation S.S.T.; synthesis and magnetization measurements J.D.; X-ray crystallography (compound 1) P.N.H. \& S.J.C. X-ray crystallography (compound 2) and discussions on magnetic data H.A.; Mössbauer spectroscopy V.S. All authors have read and agreed to the published version of the manuscript.

Funding: V.S. acknowledges the support of the research initiative NANOKAT. The PhD studies of J.D. were supported by the University of Surrey and EPSRC.

Data Availability Statement: Data available on request from the corresponding author. Data available includes raw SQUID magnetization and Mössbauer data. The crystallographic data has been submitted to the Cambridge Crystallographic Data Centre. The deposition references are CCDC 2080108 (cpd $1100 \mathrm{~K}$ ), 2080109 (cpd 2293 K). 2080110 (cpd 2100 K) and 2080111 (cpd $2290 \mathrm{~K}$ ) Available online: http://www.ccdc.cam.ac.uk/conts/retrieving.html.

Acknowledgments: S.S.T. would like to express his gratitude to Peter Day FRS with whom he worked for 10 years at the Royal Institution of Great Britain. Peter's passion, drive and scientific insight continues to provide inspiration to study the fascinating topic of molecular materials.

Conflicts of Interest: The authors declare no conflict of interest. The funders had no role in the design of the study; in the collection, analyses, or interpretation of data; in the writing of the manuscript, or in the decision to publish the results.

\section{References}

1. Cambi, L.; Szegö, L. The magnetic susceptibility of complex compounds. Ber. Deutsch. Chem. Ges. 1931, 64, 2591-2598. [CrossRef]

2. Cambi, L.; Malatesta, L. Magnetism and polymorphy of internal complex salts-Iron salts ofdithio-carbonicamide acids. Ber. Deutsch. Chem. Ges. 1937, 70, 2067-2078. [CrossRef]

3. Kahn, O.; Martinez, C.J. Spin transition polymers: From materials towards memory devices. Science 1998, 179, 44-48. [CrossRef]

4. Hayami, S.; Holmes, S.M.; Halcrow, M.A. Spin-state switching in molecular materials. J. Mater. Chem. C. 2015, 3, 7775-7778. [CrossRef] 
5. Gütlich, P.; Gaspar, A.B.; Garcia, Y. Spin-state switching in iron coordination compounds. Beilstein J. Org. Chem. 2013, 9, 342-381. [CrossRef]

6. Bonhommeau, S.; Guillon, T.; Daku, L.M.L.; Demont, P.; Costa, J.S.; Létard, J.F.; Molnár, G.; Bousseksou, A. Photoswitching of the dielectric constant of the spin-crossover complex $\left[\mathrm{Fe}(\mathrm{L})(\mathrm{CN})_{2}\right] \cdot \mathrm{H}_{2} \mathrm{O}$. Angew. Chem. Int. Ed. 2006, 45, 1625-1629. [CrossRef]

7. Guilon, T.; Bonhommeau, S.; Costa, J.S.; Zwick, A.; Létard, J.F.; Demont, P.; Molnár, G.; Bousseksou, A. On the dielectric properties of the spin-crossover complex $\left[\mathrm{Fe}(\mathrm{bpp})_{2}\right]\left[\mathrm{BF}_{4}\right]_{2}$. Phys. Status Solidi A Appl. Mat. Sci. 2006, 203, 2974-2980. [CrossRef]

8. Schäfer, B.; Bauer, T.; Faus, I.; Wolny, J.A.; Dahms, F.; Fuhr, O.; Lebedkin, S.; Wille, H.C.; Schlage, K.; Chevalier, K.; et al. A luminescent $\mathrm{P}_{\mathrm{t} 2} \mathrm{Fe}$ spin-crossover complex. Dalton Trans. 2017, 46, 2289-2302. [CrossRef]

9. Wang, C.F.; Li, R.F.; Chen, X.Y.; Wei, R.J.; Zheng, L.S.; Tao, J. Synergistic spin-crossover and fluorescence in one-dimensional hybrid complexes. Angew. Chem. Int. Ed. 2015, 54, 1574-1577. [CrossRef]

10. Jiao, Y.; Zhu, J.P.; Guo, Y.; He, W.J.; Guo, Z.J. Synergetic effect between spin-crossover and luminescence in the $\left[\mathrm{Fe}\left(\mathrm{bpp}_{2}\right)_{2}\right]\left[\mathrm{BF}_{4}\right]_{2}$ (bpp=2,6-bis(pyrazol-1-yl)pyridine complex. J. Mater. Chem. C 2017, 5, 5214-5222. [CrossRef]

11. Nihei, M.; Takahashi, H.; Nishikawa, H.; Oshio, H. Spin-crossover behavior and electrical conduction property in iroj(II) complexes with tetrathiafulvalene derivatives. Dalton Trans. 2011, 40, 2154-2156. [CrossRef]

12. Halcrow, M.A. Structure-function relationships in molecular spin-crossover complexes. Chem. Soc. Rev. 2011, 40, 4119-4142. [CrossRef] [PubMed]

13. Boillot, M.L.; Weber, B. Mononuclear ferrous and ferric complexes. Compte. Rendus. Chim. 2018, 1196-1208. [CrossRef]

14. Kumar, K.S.; Ruben, M. Emerging trends in spin-crossover (SCO) based functional materials. Coord. Chem. Rev. 2017, 346, 176-205. [CrossRef]

15. Halcrow, M.A. The synthesis and coordination chemistry of 2, 6-bis(pyrazolyl)pyridines and related ligands-Versatile terpyridine analogues. Coord. Chem. Rev. 2005, 249, 2880-2908. [CrossRef]

16. Halcrow, M.A. Iron(II) complexes of 2,6-di(pyrazol-1-yl)pyridines-A versatile system for spin-crossover research. Coord. Chem. Rev. 2009, 253, 2493-2514. [CrossRef]

17. Cook, L.J.K.; Mohammed, R.; Sherborne, G.; Roberts, T.D.; Alvarez, S.; Halcrow, M.A. Spin state behavior of iron(II)/dipyrazolylpyridine complexes. New insights from crystallographic and solution measurements. Coord. Chem. Rev. 2015, 289, 2-12. [CrossRef]

18. Coronado, E.; Galán-Mascarós, J.R.; Giménez-López, M.C.; Almeida, M.; Waerenborgh, J.C. Spin-crossover Fe(II) complexes as templates for bimetallic oxalate-based 3D magnets. Polyhedron 2007, 26, 1838-1844. [CrossRef]

19. Cassoux, P.; Valade, L.; Kobayashi, H.; Kobayashi, A.; Clark, R.A.; Underhill, A.E. Molecular metals and superconductors derived from metal complexes of 1,3-dithiol-2-thione-4,5-dithiolate (dmit). Coord. Chem. Rev. 1991, 110, 115-160. [CrossRef]

20. Robertson, N.; Cronin, L. Metal bis-1,2-dithiolene complexes in conducting or magnetic crystalline assemblies. Coord. Chem. Rev. 2002, 227, 93-127. [CrossRef]

21. Cassoux, P. Molecular (super)conductors derived from bis-dithiolate metal complexes. Coord. Chem. Rev. 1999, 185, $213-232$. [CrossRef]

22. Dorbes, S.; Valade, L.; Real, J.A.; Faulmann, C. [Fe(sal 2 -trien)][Ni(dmit $\left.)_{2}\right]$; towards switchable spin crossover molecular conductors. Chem. Comm. 2005, 69-71. [CrossRef] [PubMed]

23. Szilágyi, P.A.; Dorbes, S.; Molnár, G.; Real, J.A.; Homonnay, Z.; Faulmann, C.; Bousseksou, A. Temperature and pressure effects on the spin state of ferric ions in the $\left[\mathrm{Fe}\left(\mathrm{sal}_{2}\right.\right.$-trien $\left.)\right]\left[\mathrm{Ni}(\mathrm{mnt})_{2}\right]$ spin crossover complex. J. Phys. Chem. Solids 2008, 69, 2681-2686. [CrossRef]

24. Faulmann, C.; Szilágyi, P.A.; Jacob, K.; Chahine, J.; Valade, L. Polymorphism and its effects on the magnetic behaviour of the [Fe( sal $_{2}$-trien)][Ni(dmit) $)_{2}$ s spin-crossover complex. New J. Chem. 2009, 33, 1268-1276. [CrossRef]

25. Faulmann, C.; Dorbes, S.; Real, J.A.; Valade, L. Electrical conductivity and spin crossover: Towards the first achievement with a metal bis-dithiolene complex. J. Low Temp. Phys. 2006, 142, 261-266. [CrossRef]

26. Faulmann, C.; Dorbes, S.; de Bonneval, W.G.; Molnár, G.; Bousseksou, A.; Gomez-Garcia, C.J.; Coronado, E.; Valade, L. Towards molecular conductors with a spin-crossover phenomenon: Crystal structures, magnetic properties and Mössbauer spectra of [Fe(salten)Mepepy][M(dmit) 2 ]. Eur. J. Inorg. Chem. 2005, 16, 3261-3270. [CrossRef]

27. Takahashi, K.; Cui, H.B.; Okano, Y.; Kaboyashi, H.; Einaga, Y.; Sato, O. Electrical conductivity modulation coupled to a highspin-low-spin conversion in the molecular system $\left[\mathrm{Fe}-\mathrm{III}(\mathrm{qsal})_{2}\right]\left[\mathrm{Ni}(\mathrm{dmit})_{2}\right]_{3} \cdot \mathrm{CH}_{3} \mathrm{CN} \cdot \mathrm{H}_{2} \mathrm{O}$. Inorg. Chem. 2006, 45, 5739-5741. [CrossRef] [PubMed]

28. Nihei, M.; Tahira, H.; Takahashi, N.; Otake, Y.; Yamamura, Y.; Saito, K.; Oshio, H. Multiple bistability and tristability with dual spin-state conversions in $\left[\mathrm{Fe}(\mathrm{dpp})_{2}\right]\left[\mathrm{Ni}(\mathrm{mnt})_{2}\right] \cdot \mathrm{MeNO}_{2}$. J. Am. Chem. Soc. 2010, 132, 3553-3560. [CrossRef]

29. Farrugia, L.J. WinGX and ORTEP for Windows: An update. J. Appl. Cryst. 2012, 45, 849-854. [CrossRef]

30. Ketkaew, R.; Tabtirungrotechai, Y.; Harding, P.; Chastanet, G.; Guionneau, P.; Machivie, M.; Harding, D.J. OctaDist: A tool for calculating distortion parameters in spin crossover and coordination complexes. Dalton Trans. 2021, 50, 1086-1096. [CrossRef]

31. Ribera, A.; Rovira, C.; Veciana, J.; Tarrés, J.; Canadell, E.; Rousseau, R.; Molins, E.; Mas, M.; Schoeffel, J.P.; Pouget, J.P.; et al. The $\left[(\mathrm{DT}-\mathrm{TTF})_{2} \mathrm{M}(\mathrm{mnt})_{2}\right.$ ] family of radical ion salts: From a spin ladder to delocalized conduction electrons that interact with localized magnetic moments. Chem. Eur. J. 1999, 5, 2025. [CrossRef]

32. Elhaïk, J.; Money, V.A.; Barrett, S.A.; Kilner, C.A.; Evans, I.R.; Halcrow, M.A. The spin states and spin-crossover behaviour of iron(II) complexes of 2,6-dipyrazol-1-ylpyrazine derivatives. Dalton Trans. 2003, 10, 2053-2060. [CrossRef]

33. Bain, G.A.; Berry, J.F. Diamagnetic corrections and Pascal's constants. J. Chem. Educ. 2008, 85, 532-536. [CrossRef] 
34. Sheldrick, G.M. Crystal structure refinement with SHELXL. Acta. Cryst. C 2015, 71, 3-8. [CrossRef] [PubMed]

35. Betteridge, P.W.; Carruthers, J.R.; Cooper, R.I.; Prout, K.; Watkin, D.J. CRYSTALS version 12: Software for guided crystal structure analysis. J. Appl. Cryst. 2003, 36, 1487. [CrossRef]

36. Jameson, D.L.; Goldsby, K.A. 2,6-bis(N-pyrazolyl)pyridines-The convenient synthesis of a family of planar tridentate $\mathrm{N}_{3}$ ligands that are terpyridine analogs. J. Org. Chem. 1990, 55, 4992-4994. [CrossRef] 